ISSN (print) $0867-2008$ / ISSN (online) 2391-7512

DOI: http://dx.doi.org/10.12775/OM.2021.006

LÁsZló PósÁN*

Debreceni Egyetem

Tortenelmi Intezet

Egyetem ter 1

H-4032 Debrecen

Hungary

posan.laszlo@arts.unideb.hu

\title{
NICOLAUS VON REDEWITZ - EIN DIPLOMAT UND INFORMANT DES DEUTSCHEN ORDENS AM HOF VON SIGISMUND VON LUXEMBURG
}

\section{KEYWORDS}

history; the Middle Ages; military orders; Teutonic Order; Turks; Banate of Severin; borders; Nicolaus von Redewitz

\section{ABstract \\ Nicolaus von Redewitz - the Teutonic Order's diplomat and informant in the court of Sigismund of Luxembourg}

At the end of 1422, Sigismund of Luxembourg, King of Hungary and Holy Roman Emperor, allowed the Teutonic Order to have a permanent diplomatic representation in his court, in the person of Nicolaus von Redewitz. This was related to the fact that from the beginning of the I 420 , the Ottoman Empire posed an increasingly serious threat to the southern borders of Hungary again, and Sigismund wanted to win over the Order for the fight against the Turks. Arriving in the court of the king, von Redewitz kept the Grand Master of the order informed of Sigismund's political plans, decisions, negotiations, military actions against the Turks, and all-important events. A recurring theme in his letters was the king's urge that the Order take on the defence of the southern borders of the Hungarian Kingdom. In return, he first offered the Grand Master the Burzenland in Southern Transylvania, from where Andrew II, King of Hungary, expelled the Order in I 225, then the Banate of Severin by the lower Danube. Following long negotiations, at the end of July I 429, a few Teutonic Knights arrived in Hungary. These knights did not undertake the armed protection of the southern borders, only its organisation. Sigismund entrusted the management of twenty-one fortresses and military watch-posts to the Knights, who envisioned the reinforcement of the defence with the involvement of mercenaries. However, the

* ORCID: https://orcid.org/0000-000 I-7309-0754 
Hungarian Treasury was unable to provide the expenses for this plan. When, at the end of the summer of I 432 , the Turks launched an attack at the lower Danube, they managed to occupy three fortresses under the control of the Order. Recognising that the Order's idea of the protection of the borders is impossible to finance, at the end of 1434 , Sigismund agreed to the gradual return of the Teutonic Knights who had arrived in Hungary in I 429 to Prussia.

S igismund von Luxemburg erlaubte in seiner Urkunde vom 26. Dezember I 422, dass sich Ritter Nicolaus von Redewitz als ständiger Gesandter des Deutschen Ordens an seinem Hof aufhalten und ihn überallhin begleiten dürfe. Dank dieser Erlaubnis konnte der Deutsche Orden eine ständige diplomatische Vertretung am Hof des ungarischen und römisch-deutschen Königs haben. ${ }^{1}$ Schon etwa 200 Jahre zuvor gewährte Kaiser Friedrich II. im Jahre I 216 dem Deutschen Orden die Gnade, einen Vertreter und dessen Begleitung am kaiserlichen Hof zu haben und ständige diplomatische Aufgaben ausführen zu dürfen. ${ }^{2}$ Nach der Zeit von Friedrich II. wurde diese Gnade bis zur Zeit von Sigismund nicht erneuert. Nach dem Scheitern des Krieges zwischen Polen und dem Orden im Jahre I 422, in dem Sigismund den Orden unterstützte, ${ }^{3}$ und nach dem Friedensvertrag von Melnosee (27. September I 422) ${ }^{4} \mathrm{kam}$ Sigismund auf die Idee, eine ständige Vertretung des Deutschen Ordens an seinem Hof zu etablieren. Er wollte in den böhmischen Angelegenheiten sowie bei seinen politischen Zielen gegen den polnischen König Władysław Jagiełło und den litauischen Großfürsten Vytautas auf den Deutschen Orden zählen können und erklärte in mehreren Briefen, dass er den Orden in allen Fällen unterstütze. ${ }^{5}$ Nach dem dreimonatigen Krieg im Jahre 1422 wollte auch der Hochmeister, dass der Orden einen ständigen Ge-

I Berlin, Geheimes Staatsarchiv Preußischer Kulturbesitz (weiterhin als: GStA PK), XX. HA, Ordensbriefarchiv (weiterhin als: OBA), Nr. 40 Io.

2 Marie-Luise Favreau-Lilie, "Der Deutsche Orden in Norditalien (1 3. Jh.). Über die Grenzen der 'Netzwerkforschung', Ordines Militares Colloquia Torunensia Historica. Yearbook for the Study of the Military Orders 20 (2015): 46.

3 Die am 29. August 1422 erlassene Urkunde rief die Stadt Bartfeld auf, ihre Kaufleute aus Polen nach Hause zu rufen, weil sich Sigismund auf einen Krieg gegen König Jagiello vorbereitete. Zsigmondkori oklevéltár, Bd. IX, hrsg. v. Norbert C. Tóth (Budapest: Magyar Országos Levéltár, 2004), Nr. 914. Sigismund rief auch die Stände des Reiches zur Unterstützung des Deutschen Ordens auf. Jörg K. Hoensch, Kaiser Sigismund. Herrscher an der Schwelle zur Neuzeit 1368-1437 (München: C. H. Beck, 1996), 302-303.

4 Über den Krieg zwischen Polen und dem Deutschen Orden im Jahre I 422 siehe Sven Ekdahl, "Der Krieg zwischen dem Deutschen Orden und Polen-Litauen im Jahre I 422," Zeitschrift für Ostforschung I 3 , H. 4 (1964): 61 4-65 I.

5 Regesta Imperii XI. Die Urkunden Kaiser Sigmunds (I4IO-I437), Bd. I, hrsg. v. Johann F. Böhmen (Innsbruck: Wagner, I 896), Nrn. 5368, 542 1, 5426. 
sandten am Hof des Kaisers hat. Ende des Jahres kam Ritter von Redewitz am Hof an. Die Urkunde des Kaisers (26. Dezember) bezüglich des ständigen Gesandten des Ordens beschreibt die Fakten, die schon während der vorherigen Verhandlungen festgelegt worden waren. Der Ritter erschien also schon vor dem Erlass der Urkunde am Hof des Kaisers.

\section{FORSCHUNGSSTAND}

Die Persönlichkeit und Tätigkeit von Nicolaus von Redewitz erschienen in der historischen Forschung vor allem im Zusammenhang mit König Sigismunds Verhältnis zum Deutschen Orden. Die im Jahre I 846 erschienene Studie von Joseph Kemény Die durch König Sigmund im Jahre 1426 beabsichtigte Wiederansiedlung des Deutschen Ordens in Siebenbürgen ${ }^{6}$ eröffnete den Weg für neue Werke, die sich mit der Einladung des Deutschen Ordens zur südlichen Grenze Ungarns beschäftigten. Frigyes Pesty widmete in der zweiten Hälfte des I 9. Jahrhunderts in seinen Büchern A szörényi bánság és Szörény vármegye története [Die Geschichte des Banats von Severin und des Komitats Severin] und Krassó vármegye története [Die Geschichte des Komitats Karasch] der Einladung des Deutschen Ordens nach Severin viel Aufmerksamkeit. Seinen Werken fügte er auch eine Dokumentenversammlung bei. ${ }^{7}$ In den I 940er Jahren schrieben Victor Montogna, ${ }^{8}$ und Ioan I. Nistor ${ }^{9}$ über die Geschichte des Banats und die dortige Tätigkeit des Deutschen Ordens. Theodor N. Trâpcea ${ }^{10}$ und später im Jahre 2009 Dumitru Ţeicu ${ }^{11}$ erwähnten den Deutschen Orden in ihren über die mittelalterlichen Burgen im Banat geschriebenen Studien. Andere Autoren behandelten die Tätigkeit des Deutschen

6 Joseph Kemény, "Die durch König Sigmund im Jahre 1426 beabsichtigte Wiederansiedlung des deutschen Ordens in Siebenbürgen," in Magazin für Geschichte, Literatur und alle Denk- und Merkwürdigkeiten Siebenbürgens, Bd. II/ I, hrsg. v. Anton Kurz (Kronstadt: Johann Gott Verlag), 98-99.

7 Frigyes Pesty, A szörényi bánság és Szörény vármegye története, Bd. I-3 (Budapest: Akadémiai, I 878); ders., Krassó vármegye története, Bd. I-3 (Budapest: Athenaeum, I 882).

8 Victor Montogna, "Banatul românesca în prima jumătate a secolului XV. Epocha lui Sigismund de Luxemburg (1 395-1 438)," in Banatul de altădată. Studii istorice, hrsg. v. Cornel Grofşorean (Timişoara: Institutului Social Banat-Crişana, 1944), 458-460.

9 Ioan I. Nistor, Ţara Severinului şi Banatul Timişan (Bucureşti: Monitorul Oficial si Imprimeriile Statului, 1945), 30-33.

Io Theodor N. Trâpcea, "Despre unele cetăți medievale din Banat," Studii de istorie a Banatului I (1969): 23-82.

11 Dumitru Țeicu, "Cetăti medievale din Banat," Reşita: Muzeul Banatului Montau (2009): I I - I6. 
Ordens als Teil der Außenpolitik von Sigismund. ${ }^{12}$ Einige Werke befassten sich mit der Severiner Periode als Teil der allgemeinen Geschichte des Ordens. ${ }^{13}$ Die Tätigkeit des Ordens an der Niederdonau beschrieb zuerst Erich Joachim im Jahre I 9 I 2, seiner Studie legte er auch Urkunden bei. Seine Ergebnisse waren lange Zeit maßgebend, ${ }^{14}$ und erst in den $1970 e r$ Jahren nahm das Interesse an Severin in der Zeit von Sigismund und der militärischen Grenzschutztätigkeit des Deutschen Ordens an der Niederdonau zu. ${ }^{15}$ Anfang der I 990er Jahre bearbeitet Jenő Glück bisher nicht publizierte Urkunden in seinen Studien, ${ }^{16}$ kürzlich publizierte Costin

12 Şerban Papacostea, "Kilia et la politique orientale de Sigismund de Luxembourg," Revue Roumaine d'Histoire I 5 (1976): 430-43 I ; Elemér Mályusz, Zsigmond király uralma Magyarországon 1387-1437 (Budapest: Gondolat, I 984); Hoensch, Kaiser Sigismund, 343-345; Harald Zimmermann, "Kaiser Sigismund von Luxemburg und Siebenbürgen," in ders., Siebenbürgen und seine Hospites Teutonici. Vorträge und Forschungen zur südostdeutschen Geschichte. Festgabe zum 70. Geburtstag, hrsg. v. Konrad Gündisch (Köln-Weimar-Wien: Böhlau, I996), I I 8; ders., "Europäische Politik und Türkenabwehr zur Zeit Sigismunds des Luxemburgers," in ebd., I 28- I 29; László Pósán, “Zsigmond és a Német Lovagrend," Hadtörténelmi Közlemények I I I (1998): 108-1 10; Mark Whelan, "Catastrophe or Consolidation? Sigismund's Response to Defeat after the Crusade of Nicopolis (1 396)," in Between Worlds: The Age of the Jagiellonians, hrsg. v. Florin Ardelean, Christopher Nicholson, und Johannes Preiser-Kapeller (Frankfurt/ Main: Peter Lang, 2013), 2 I 5-227.

13 Johannes Voigt, Geschichte Preussens von den ältesten Zeiten bis zum Untergang der Herrschaft des Deutschen Ordens, Bd. 7 (Königsberg: Gebrüder Bornträger, I 836), 502-503, 534-535; Kurt Forstreuter, "Der Deutsche Orden und Südosteuropa," Kyrios I (1936): 259-260; Walter Kuhn, "Ritterorden als Grenzhüter des Abendlandes gegen das östliche Heidentum," Ostdeutsche Wissenschaft 6 (1959): 59-66; Carl A. Lückerath, Paul von Russdorf. Hochmeister des Deutschen Ordens 1422-I44I (Bad Godesberg: Wissenschaftliches Archiv, 1969), 8 I-85; Harald Zimmermann, Der Deutsche Orden in Siebenbürgen. Eine diplomatische Untersuchung (Köln-Weimar-Wien: Böhlau, 20 I I), 9-10, 34-35.

14 Erich Joachim, "König Sigmund und der deutsche Ritterorden in Ungarn I 429-1 432," Mitteilungen des Instituts für österreichische Geschichtsforschung 33, H. I ( I 9 I 2): 87- I 19.

is Alexandru Nemoianu, "Unele aspecte privind prezența teutonilor în Banat (1429-1432)," Muzeul Național 2 (1975): 38 I-386; Ioan Hațegan, "Cavalerii teutoni în Banatul Severinului (1429-1435)," Tibiscus 5 (1979): 191-196; Viroel Achim, "Der Stellenwert des Deutschen Ordens in der Geschichte des Banats von Severin," in Generalprobe Burzenland: Neue Forschungen zur Geschichte des Deutschen Ordens in Siebenbürgen und im Banat. Harald Zimmermann zum 85. Geburtstag, hrsg. v. Konrad Gündisch (Köln-Weimar-Wien: Böhlau, 201 3), 177-ı 88; Virgil Ciocîltan, "Sigismund von Luxemburg und die Frage der Verpflanzung des Deutschen Ordens an die Untere Donau in den Jahren I 41 2-1420", in ebd., 160-176; László Pósán, "A Német Lovagrend szerepe Magyarország déli határainak védelmében ( I 429-1435)," in Örzők, vigyázzatok a határra! Határvédelem, határórizet, határvadászok a középkortól napjainkig, hrsg. v. László Pósán, László Veszprémy, József Boda, und János Isaszegi (Budapest: Zrínyi, 2017), 263-292.

${ }_{16}$ Jenő Glück, "Date noi cu privire la prezența cavalerilor teutoni la frontiera Banatului ( I 429- I 437)," Revista Istorică N.F. 3 (1992): 783-792; ders., "A Német Lovagrend a XV. századi Bánságban," Zounuk. A Szolnok Megyei Levéltár Évkönyve I 8 (1993): 33-44. 
Fenesan neue Dokumente in seinem 2015 veröffentlichten Buch. ${ }^{17}$ In den Studien wurde immer erwähnt, dass Nicolaus von Redewitz an die Donau Truppen des Ordens führte, und Sigismund ihn mit höheren Ämtern bekleidete, aber seine Tätigkeit wurde anhand seiner Rolle in der ungarischen Finanzverwaltung ${ }^{18}$ und nicht aufgrund seiner diplomatischen Aufgaben beurteilt.

\section{Die Türkengefahr bei Der SÜdgrenze von UngarN}

Das Erscheinen von Nicolaus von Redewitz als Gesandter am Hof von Sigismund hatte eine Vorgeschichte. Hochmeister Paul von Rusdorf schickte im Frühling I 422 Witich von der Pforten, der vorher unter anderem beim Lieger des Ordens in Brügge tätig war, als diplomatischen Beauftragten nach Ofen, um mit seiner Hilfe den ungarischen König bei Handelsfragen zu unterstützen. ${ }^{19}$ Man kann vermuten, dass er den Hochmeister über alle Geschehnisse am Hof unterrichten musste. Weil er mit Handelsfragen betraut war, konnte er jedoch über viele Geschehnisse nicht berichten. Der Orden brauchte also jemanden, der auch über die politischen Angelegenheiten berichten konnte. Es ist vorstellbar, dass die Verhandlungen über einen zu delegierenden Gesandten gerade über Witich von der Pforten verliefen.

Sigismund hielt die Anwesenheit eines ständigen Gesandten des Deutschen Ordens nicht nur wegen der Eroberung des böhmischen Throns, sondern auch wegen der Türkengefahr für wichtig und setzte bei der Verteidigung der Südgrenzen von Ungarn auf den Orden. Um den Hochmeister und die Leiter des Ordens von diesem Anliegen zu überzeugen, hielt es der Kaiser für notwendig, ständig einen Gesandten des Ordens in seiner Umgebung zu haben, so dass der Gesandte persönlich erleben konnte, welch große Gefahr die Türken für das Christentum bedeuteten. Schon nach seinem gescheiterten Kreuzzug gegen die Türken im Jahre $1396^{20}$ wandte sich der Kaiser mit dem Angebot an den Hochmeister, dem

17 Costin Fenesan, Cavalerii teutoni în Banatul Severinului si la Dunarea de Jos în prima jumatate a seocolului al XV-lea: documente si extras (Timisoara: Cosmopolitan Art, 201 5).

18 Gerhard Hochstrasser, "Der Ordenspraeceptor Nicolaus von Redwitz und die Münzprägung in Siebenbürgen und im Seweriner Banat im I 5 . Jahrhundert," in Beiträge zur Geschichte des Deutschen Ordens, Bd. 2, hrsg. v. Udo Arnold (Marburg: Elwert, I 993), I $24-134$.

19 Wolfgang von Stromer, "Zsigmond császár Velence elleni kontinetális zárlata és a nemzetközi kereskedelmi utak áthelyeződése," Századok I 2 I (1 987): 655.

20 Über den Kreuzzug von 1396 gegen die Türken siehe Aziz Suryal Atiya, The Crusade of Nikopolis (London: Meuthen, I943); János Hóvári, "A nikápolyi csata. Fordulópont a balkáni oszmán hódítások történetében," Hadtörténelmi Közlemények I I I (1998): 578-582; Attila Bárány, "Magyarország és a kései keresztes hadjáratok," in Magyarország és a keresztes háborúk. 
Orden das Burzenland, ${ }^{21}$ aus dem der Orden 1225 von König Andreas II. vertrieben worden war, zurückzugeben, wenn der Orden dafür die südliche Grenze des Landes verteidige. Aus den langen Verhandlungen kann man schlussfolgern, dass Sigismund hoffte, dass der Orden viele Soldaten aus Preußen zu den ungarischen Grenzen kommandieren würde. Das Anliegen des ungarischen Königs fand I 397 noch keinen Anklang in Marienburg. Nachdem Sultan Bayezid I 402 von Timur eine schwere Niederlage zugefügt worden war und das Osmanische Reich in Teile zerfallen war, ${ }^{22}$ war im ersten Jahrzehnt des i 5 . Jahrhunderts die unmittelbare türkische Gefahr an den ungarischen Grenzen und damit auch die Einladung des Deutschen Ordens nach Ungarn vom Tisch. Nach dem Zerfall des Osmanischen Reiches verstärkte der ungarische König die aus den balkanischen Vasallenstaaten bestehende äußere Schutzzone, womit die Sicherheit der Südgrenzen garantiert zu sein schien. Obwohl die Türken nach I 402 keine Gefahr mehr für das christliche Europa darstellten, ermunterte die polnische Delegation Anfang 14I6 auf dem Konstanzer Konzil den Deutsche Orden, zu seiner ursprünglichen Tätigkeit, gegen die Heiden zu kämpfen, zurückzukehren, denn mit der Bekehrung von Litauen zum Christentum gab es im Baltikum dafür keine Gelegenheit mehr. Die polnische Delegation schlug vor, dass der Orden aus Preußen an die türkische oder tatarische Grenze übersiedeln solle. ${ }^{23}$ Der Generalprokurator des Deutschen Ordens schrieb in seinem Brief vom 28. Juni 1416 an den Hochmeister, dass die polnische Delegation auf dem Konstanzer Konzil vorschlug, dass der Orden nach Zypern oder Podolien übersiedeln solle. ${ }^{24}$ I 4 I 8, im Schlussjahr des Konzils, als Dan II., der neue Fürst der Walachei, statt der ungarischen Krone zu folgen, Va-

Lovagrendek és emlékeik, hrsg. v. József Laszlovszky, Judit Majorossy, und József Zsengellér (Máriabesnyő-Gödöllő: Attraktor, 2006), I 46-I 49.

${ }_{21}$ Codex diplomaticus Prussicus, Bd. VI, hrsg. v. Johannes Voigt (Königsberg: Gebrüder Bornträger, I 86 I), Nr. 49.

22 Pál Fodor, The Unbearable Weight of Empire. The Ottomans in Central Europe - A Failed Attempt at Universal Monarchy (1390-1566) (Budapest: MTA BTK TTI, 20 I 5), 34 ; József Matuz, Az Oszmán Birodalom története (Budapest: Akadémiai, I 990), 38.

23 Matthias Thumser, "Eine neue Aufgabe im Heidenkampf? Pläne mit dem Deutschen Orden als Vorposten gegen die Türken," in Europa und die Türken in der Renaissance, hrsg. v. Bodo Gurthmüller (Tübingen: De Gruyter, 2000), I 4 I-I 42; László Pósán, "Die politischen Bestrebungen und Ziele Polen-Litauens auf dem Konstanzer Konzil," in Der Deutsche Orden auf dem Konstanzer Konzil. Pläne - Strategien - Erwartungen, Quellen und Studien zur Geschichte des Deutschen Ordens 84, hrsg. v. Helmut Flachenecker (Würzburg: Forschungsstelle Deutscher Orden an der Universität Würzburg, 2020), 97.

${ }_{24}$ Die Berichte der Generalprokuratoren des Deutschen Ordens an die Kurie, Bd. II, Peter von Wormditt (1403-I4I9), hrsg. v. Kurt Forstreuter und Hans Koeppen (Göttingen: Vandenhoeck \& Ruprecht, 1961), Nr. I64. 
sall des Sultans wurde, ${ }^{25}$ beschäftigte sich Sigismund wieder mit der Verteidigung der Südgrenzen. Er wollte die Flotte auf der Donau verstärken und flämische Schiffszimmermänner (navifactores, magistros et opifices galliatarum) nach Ungarn einladen. ${ }^{26}$ Nachdem Mehmed I. (1413-142 I) das Osmanische Reich wiedervereinigt hatte, wurden die Türken ab den I $420 e r$ Jahren auf dem Balkan wieder aktiver. Sigismund musste die der ungarischen Krone loyalen rumänischen und serbischen Fürsten ${ }^{27}$ mit vielen und kostspieligen Kriegszügen unterstützen. Neben den Kriegszügen ließ er an der Südgrenze entlang der Donau viele neue Burgen bauen. ${ }^{28}$ Im Mai 1426 kam er mit dem serbischen Fürsten Lazarević überein, dass für die Anerkennung des Erbrechts seines Neffen Đurađ Branković die wichtigen serbischen Burgen an der rechten Seite der Donau, wie Belgrad und Golubac, unter die Oberhoheit der ungarischen Krone kommen sollten. ${ }^{29}$

\section{Die TÄtigkeit von Nicolaus von RedeWitz ZWischen i 422 UND I 428}

Der Delegierte des Ordens Nicolaus von Redewitz, der Ende 1422 nach Ungarn kam, war Augenzeuge dieser Geschehnisse. Es ist vorstellbar, dass auf Empfehlung von von Redewitz ab Herbst 1424 zwei preußische Kaufleute, Johann Falbrecht aus Thorn und David Rodenfeld aus Kulm, in der ungarischen Finanzverwaltung arbeiteten. Sie waren vorher als Beauftragte des Großschäffers des Ordens tätig und gründeten später eine eigene Handelsgesellschaft, die unter anderem auch mit ungarischen Produkten, vor allem mit Kupfer, handelte. I 424 erwarben sie Beteiligungen an einem Bergbauunternehmen und kamen selbst mit dem König in Handelskontakt. ${ }^{30}$ Im Gegenzug für dem König gegebene Darlehen bekamen sie die Münzanstalten in Kremnitz und Kaschau sowie die Steuer der Bergstädte in

25 Gábor Ágoston, Európa és az oszmán hóditás (Budapest: HM HIM, 2014 ), 267.

26 Zsigmondkori oklevéltár, Bd. VI, hrsg. v. Elemér Mályusz und Iván Borsa (Budapest: Akadémiai, I 999), Nr. I 565 .

27 Ágoston, Európa, 267.

28 Costin Feneşan, "Cavalerii Teutoni in Banatul Severinului şi la Dunărea de jos în prima jumătate a secolului al XV-lea. Documente şi extrase," Banatica 26 (2016): I3; Țeicu, Cetăti medievale, 74-I I 4 .

29 Mályusz, Zsigmond király, i 6 .

30 Miroslav Lacko und Erika Mayerová, Das älteste Stadtbuch von Schmöllnitz 1410-1735. Eine Quelle zu den mitteleuropäischen wirtschaftlichen Verflechtungen (Limbach: Slovenská spoločnost pre sociálne a hospodárske dejiny, 2016), 34-38; Renáta Skorka und Boglárka Weisz, "A porosz kapcsolat. Johann Falbrecht és David Rosenfeld a magyar pénzügyigazgatásban," in Hatalom, adó, jog. Gazdaságtörténeti tanulmányok a magyar középkorról, hrsg. v. István Kádas und Boglárka Weisz (Budapest: MTA BTK TTI, 2017), I 8 I-1 83. 
Unter- und Oberungarn. ${ }^{3}$ Nicolaus von Redewitz muss von ihrer Tätigkeit und ihrer Rolle bei der ungarischen Wirtschaftsführung gewusst und mit beiden Männern Kontakt gehabt haben. Neben den die Südgrenzen betreffenden Angelegenheiten musste sich Sigismund auch mit den böhmischen Sachen beschäftigen und berief im Januar 1425 in Wien einen Reichstag ein, um über ein Auftreten gegen die hussitischen Ketzer zu verhandeln. Er blieb vom 6. Januar bis zum 3. Februar 1425 in Wien. ${ }^{32}$ Nicolaus von Redewitz, der ständige Gesandte des Deutschen Ordens, fuhr mit der Hofhaltung des Königs nach Wien und unterrichtete den Hochmeister regelmäßig auftragsgemäß über die wichtigsten politischen Geschehnisse, die sich in der Umgebung des Königs ereigneten. Sigismund hielt es selbst auch für wichtig, den Deutschen Orden über seine Entscheidungen und Pläne zu informieren, denn Ritter von Redewitz berichtete in seinem Brief vom I9. Januar I 425 über Pläne des Königs, die er vom König selbst gehört hatte. Weiterhin erläuterte er auch den Stand der Hussitenkriege, das Verhältnis des Kaisers zu Dänemark, über die Reise des dänischen Königs in das Heilige Land, wen Sigismund zum Erzbischof von Riga empfehle und auch darüber, dass die Gerüchte über den Tod von Dan II., des Fürsten der Walachei. und Vasallen der ungarischen Krone, nicht wahr seien. ${ }^{33}$ In einem anderen Brief schrieb er dem Hochmeister, dass Sigismund überlege, dem Orden die Provinz Neumark nicht als Pfand, sondern als Eigentum zu überlassen. ${ }^{34}$ Über die Anwesenheit von Nicolaus von Redewitz am Hof von Sigismund berichtete auch der dänische König Erik in seinem Brief an den Hochmeister vom 2. März I 425, in dem er dem Orden versicherte, beim Kaiser immer die Interessen der Ritter zu befürworten. ${ }^{35}$ Der Gesandte des Ordens schickte seinen nächsten Brief am 20. März I 425 aus der Stadt Kaschau in Nordostungarn nach Marienburg, in dem er die Verhandlungen zwischen dem dänischen König und Sigismund zusammenfasste. ${ }^{36}$ Der ungarische König und mit ihm auch Ritter von Redewitz verließen Ungarn Ende September I 425 und zogen gegen die Hussiten, kehrten aber Ende des Jahres zurück, ${ }^{37}$ weil Berichte über die Bewegung der Türken im Süden eintra-

${ }_{31}$ Regesta Imperii, XI, I, hrsg. v. Böhmen, Nr. 5985 ; Skorka und Weisz, "A porosz kapcsolat," I 83 $-193$.

32 Friedrich von Bezold, König Sigmund und die Reichskriege gegen die Hussiten (München: Ackermann, I 872), 80 .

33 GStA PK, XX. HA, OBA, Nr. 4378.

34 GStA PK, XX. HA, OBA, Nr. 4397.

35 GStA PK, XX. HA, OBA, Nr. 4398.

36 GStA PK, XX. HA, OBA, Nr. 4407.

37 Itineraria regum et reginarum $(1382-1438)$, hrsg. v. Pál Engel und Norbert C. Tóth (Budapest: MTA TTI, 2005), I I 8-i i 9 . 
fen. ${ }^{38}$ Nachdem Sigismund im Mai 1426 mit dem serbischen Fürsten die Übernahme der Burgen an den serbischen Grenzen entlang der Donau vereinbart hatte, erneuerte der König seine Einladung an den Deutschen Orden, nach Ungarn zu kommen. So wie im Jahre 1397 wollte er auch jetzt den Orden mit der Verteidigung der Südgrenzen in Siebenbürgen beauftragen. Er schrieb am 2. Juli I 426 einen Brief an den siebenbürgischen Woiwoden, die siebenbürgischen Adligen und die siebenbürgischen Sachsen, in dem er Folgendes berichtete: „Da die südlichen Teile von Siebenbürgen von der ständigen Räuberei der Türken bedroht sind, haben wir daran gedacht, dass wir dem Beispiel von König Andreas II. folgend den Deutschen Orden in die südlichen Teile von Siebenbürgen bis zum Eisernen Tor einladen, damit er die Grenzen verteidigen kann.“"39 Weiterhin fragte er die Adressierten, ob sie mit der Übersiedlung des Ordens nach Südsiebenbürgen einverstanden seien. Da spätere Quellen nichts über eine Übersiedlung des Ordens nach Siebenbürgen berichten, kann man annehmen, dass die Gefragten, vor allem die Sachsen, deren Gebiete von dem Plan betroffen gewesen wären, nicht begeistert waren, unter die Oberhoheit eines ritterlichen Mönchsordens zu geraten und möglicherweise ihre Privilegien zu verlieren. Nicolaus von Redewitz muss den Hochmeister informiert haben, was die Siebenbürger von der Idee einer Übersiedlung des Deutschen Ordens hielten, und auch darüber, mit welchem Vorschlag Sigismund nach der vermutlich abweisenden Antwort der Siebenbürger kam. Er wollte den Deutschen Orden nicht mit der Verteidigung der Südgrenzen Siebenbürgens vom Burzenland bis zum Eisernen Tor, sondern mit der Verteidigung des Donaugrenzgebietes westlich vom Eisernen Tor, also des Banats von Severin, beauftragen. ${ }^{4}$ Er hoffte, dass der Orden neben der Verteidigung der Grenzen die Fürsten der Walachei militärisch unterstützen würde und man damit das System der Puffervasallenstaaten aufrechterhalten könne. ${ }^{41}$ Ende 1426 und im Frühling I 427 verblieb der ungarische König (und mit ihm auch Nicolaus von Redewitz) im Burzenland in der Nähe der Walachei, um die Position seines Vasallen Dan II. zu stärken. Am 3 I. Dezember 1426 wurden seine Urkunden noch in Kronstadt erlassen, ${ }^{42}$ doch schon im Frühling 1427 in Marienburg (Földvár/ /Feldioaru), dem siebenbürgischen Zentrum des Ordens vor 200 Jahren. Am 9. April 1427 schickte der König einen Brief an Hochmeister Paul von Rusdorf, in

${ }_{38}$ Géza Pálffy, “A török elleni védelmi rendszer szervezetének története a kezdetektől a I 8. század elejéig," Történelmi Szemle 38 (1996): 167.

39 Zsigmondkori oklevéltár, Bd. XIII, hrsg. v. Norbert C. Tóth und Gábor Mikó (Budapest: Magyar Országos Levéltár, 2017 ), Nr. 808.

$4 \circ$ Regesta Imperii, XI, I, hrsg. v. Böhmen, Nr. 6830.

${ }_{41}$ Mályusz, Zsigmond király, i 17.

${ }_{42}$ Zsigmondkori oklevéltár, XIII, hrsg. v. Tóth und Mikó, Nrn. I 503, I 504. 
dem er ihm mitteilte, dass er den Gesandten des Ordens Ritter Nicolaus von Redewitz zum Mitglied des königlichen Rates ernannt und ihn damit in den Kreis der königlichen Ratgeber und Entscheidungsträger erhoben habe. Er teilte auch mit, dass er die Niederlassung des Ordens in Ungarn und seine Teilnahme an den Türkenkriegen wünsche. Er schlug also nicht vor, dass der Orden Preußen verlässt, seine Güter dort aufgibt und irgendwohin anders übersiedelt (wie es die Gesandten des polnischen Königs auf dem Konstanzer Konzil angeregt hatten), sondern dass der Orden seiner Aufgabe gemäß am Krieg gegen die Türken teilnimmt, wozu der Ordensstaat eine stabile Basis bietet. Er bat den Hochmeister einen Amtsträger des Ordens nach Ungarn zu schicken, der zusammen mit Ritter von Redewitz die Gebiete entlang der Niederdonau, die der König dem Orden geben wollte, besichtigt. Weiterhin bat er um Flussschiffer und Ruderer, die schnellstmöglich unter Befehl der Ritter an der Donaugrenze dienen können. ${ }^{43}$ Nicolaus von Redewitz informierte zwei Tage später am I I. April den Hochmeister ausführlich über dieses Angebot und das vertrauliche Gespräch mit dem König und teilte ihm mit, dass man die Türken mit Gräben und Palisaden aufhalten wolle (mit graben und planck durch enthaldung der Torken). ${ }^{44}$ Neben den Angelegenheiten des Ordens thematisierte er auch, dass die Armee von Sigismund aus dem Burzenland in der Walachei bis zur Stadt Câmpulung, die vor den Karpaten liegt, vorgedrungen, und auf die Nachricht, dass Sultan Murad mit einem Heer von 40000 Soldaten einen Gegenangriff plane, durch den Törzburger Pass nach Siebenbürgen zurückgekehrt sei. ${ }^{45}$ Dass der Gesandte des Ordens Mitglied des königlichen Rates geworden ist, zeigt, wie hoch Sigismund auf Grund seiner Erfahrungen die persönlichen Qualitäten des Ritters von Redewitz schätzte, und beweist auch die Seriosität seiner Pläne bezüglich des Deutschen Ordens. Er schickte am 22. April 1427 wieder einen Brief an den Hochmeister, dass er Vizekanzler Kaspar Schlick nach Preußen schicken wolle, um sein Angebot über die Verteidigung der Südgrenze darzulegen. ${ }^{46}$ Noch in demselben Monat schrieb er an den bayrischen Herzog über seine Pläne gegen die Türken und meinte mit der hilfe gotes die Tunow wider eincznemen. ${ }^{47}$ Wie er das genau meinte, erklärte er in seinem Brief vom 3. Mai an den Hochmeister. Hier formulierte er seinen Perspektivplan, dass der Orden die Türken an der Niederdonau zurückdrängen solle, damit der ganze Wasserweg der

43 GStA PK, XX. HA, OBA, Nr. 4738 (Fenesan Nr. 7).

44 GStA PK, XX. HA, OBA, Nr. 474I (Fenesan Nr. 8).

45 Ebd.; Liviu Cîmpeanu, "Dan al II-lea, Sigismund de Luxemburg şi cruciada târzie. Un document inedit din archiva Ordinului teutoni," Studii şi materiale de istorie medie 30 (201 2): 74.

${ }_{46}$ GStA PK, XX. HA, OBA, Nr. 4749.

47 Deutsche Reichstagakten unter Kaiser Sigmund, Bd. IX, hrsg. Dietrich Kerler (München: Oldenburg, 1887), Nr. 29. 
Donau bis zum Schwarzen Meer unter die Oberhoheit der ungarischen Krone falle ([...] sin quad hab dann die tunaw biß in das mer gancz geweltigt). Er bat den Hochmeister um Hilfe beim krieg zuwasser und zuland gegen die Türken, bat weiterhin um 20 schiffmacher, schifhouptleute, 800 oder r 000 schifkinder, Fischer item czwene gute Bolwerkmeister. Im Gegenzug dafür war er bereit, dem Orden die verpfändete Provinz Neumark als Eigentum zu geben. ${ }^{4}$ Die Führung des Deutschen Ordens scheint Kaspar Schlick, dem Gesandten von Sigismund in Preußen, keine eindeutige Antwort gegeben zu haben, weil ein Brief vom 4. Juli 1427 belegt, dass der König Nicolaus Stock, einen neuen Gesandten, nach Preußen, Dänemark und in die wendischen Hansestädte schickte. Er bat den Hochmeister erneut, einen Beauftragten nach Ungarn zu schicken, der sich die dem Orden angebotenen Gebiete an der Südgrenze ansehen könne. Er wiederholte seine Bitte, dass der Hochmeister Schiffsbauer, Flussschiffer und Kaufleute aus Danzig und Thorn schicken solle. ${ }^{49}$ Nicolaus von Redewitz schrieb drei Wochen später am 22. Juli an den Hochmeister, dass der ungarische König in der Großen Walachei östlich vom Fluss Alt gegen die Türken Krieg führe. Er berichtete auch, wie die Prozesse des Kaisers in unterschiedlichen privaten Streitsachen standen. ${ }^{\circ}$ Am nächsten Tag informierte auch Sigismund den Hochmeister offiziell über seinen Kriegszug in die Walachei und seine Prozesse. ${ }^{51}$ Nach dem Brief des Herzogs von Mailand vom August 1427 hatte der ungarische König viele Schiffer verloren, als die Türken die ungarischen Boote und Galeeren auf der Donau ([...] arreptione naveam et galearum) überfielen..$^{2}$

Laut einem am 2. Oktober 1427 geschriebenen Brief fuhr Nicolaus von Redewitz als königlicher Ratsherr im Auftrag von Sigismund nach Schlesien, um dort mit dem Herzog von Oels über das der deutsch-römischen Krone gebührende Einkommen zu verhandeln. ${ }^{33}$ Der Ritter war einige Monate vorher zum Mitglied des ungarischen königlichen Rats berufen worden, war aber auch mit Fragen des Kaiserreichs betraut. Gemäß dem Brief des Hochmeisters Paul von Rusdorf vom 29. Juni 1428 hatte der Deutsche Orden zu diesem Zeitpunkt noch immer keine Entscheidung über das Angebot von Sigismund getroffen, in dem der König den Orden zum Schutz der Donaugrenzen aufforderte. Der Streit mit König Jagiełło über die genaue Grenze zwischen Neumark und Polen beschäftigte aber den Or-

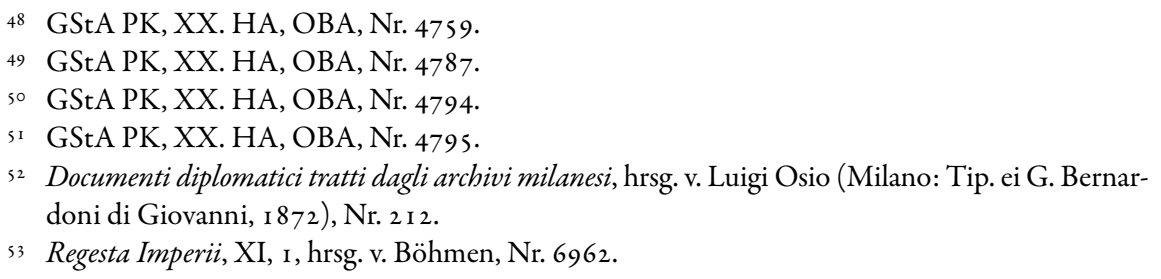


den sehr. Der Hochmeister beauftragte Nicolaus von Redewitz, in dieser Frage die Interessen des Deutschen Ordens zu vertreten, als Sigismund eine Entscheidung trifft. $^{54}$

\section{Die Verhandlungen vor der Ankunft des Deutschen Ordens IN SEVERIN}

Sigismund erlitt am 3. Juli 1428 bei Golubac (Galambóc) eine schwere Niederlage gegen die Türken. ${ }^{55}$ Dies bedeutete gleichzeitig den Zusammenbruch des auf dem System der Vasallenstaaten beruhenden Grenzschutzes, die Landesgrenze wurde die tatsächliche Verteidigungslinie und die Türken wurden dauerhaft ein unmittelbarer Nachbar des ungarischen Königreichs. In dieser Situation wollte Sigismund beim Deutschen Orden erreichen, dass dieser an der Verteidigung der Südgrenzen teilnimmt. Er schrieb am 9. Oktober 1428 einen Brief an den Hochmeister, dass er die Niederlassung des Ordens in Ungarn wünsche. Er bot dem Orden das Banat von Severin an und bat, in das Kontingent des Ordens, das zur Südgrenze geschickt wird, auch den Brückenbaumeister Hans von Ratibor aufzunehmen, weil man seine Kenntnisse brauchen werde, falls die christlichen Truppen die türkische Seite der Donau überfallen wollen. In seinem Brief ging er auch darauf ein, dass er den Gesandten des Hochmeisters Nicolaus von Redewitz über die Details der Niederlassung des Deutschen Ordens im Banat von Severin informiert habe. ${ }^{56}$ An demselben Tag schrieb Sigismund auch an den Ordensmarschall und bat um seine Unterstützung bei der Niederlassung des Ordens in Ungarn und der Teilnahme an den Feldzügen gegen die Türken bzw. der Verteidigung der Südgrenzen des Königreichs gegen die Ketzer. ${ }^{57}$ Auf das Angebot des ungarischen Königs kam sehr lange keine Antwort aus Preußen. Ein wichtiger Grund hierfür könnte die

54 Ebd., Nr. 7 Ioo.

ss Pál Engel, "Ungarn und die Türkengefahr zur Zeit Sigismunds (1387-1437)," in Das Zeitalter König Sigismunds in Ungarn und im Deutschen Reich, hrsg. v. Tilmann Schmidt und Péter Gunst (Debrecen: DUP, 2000), 67.

s6 Regesta Imperii XI. Die Urkunden Kaiser Sigmunds (I4IO-I437), Bd. 2, hrsg. v. Johann Friedrich Böhmen (Innsbruck: Wagner, I 900), Nr. 7 I 32. Über den Brückenbau des Deutschen Ordens, siehe Sławomir Jóźwiak, "Der Bau, Wiederaufbau und Ausbau der Nogatbrücke gegenüber der Marienburg vom I 4. bis zu den Anfängen des I 5. Jahrhunderts," in Studies of the Military Orders, Prussia, and Urban History: Essays in Honour of Roman Czaja on the Occasion of his Sixtieth Birthday / Beiträge zur Ritterordens-, Preußen-und Städteforschung. Festschrift für Roman Czaja zum 6o. Geburtstag, hrsg. v. Jürgen Sarnowsky, Krzysztof Kwiatkowski, Hubert Houben, László Pósán, und Attila Bárány (Debrecen: University of Debrecen, 2020), 26 I-272.

57 GStA PK, XX. HA, OBA, Nr. 4990. 
Entwicklung des polnisch-litauischen Verhältnisses sein, das ein unsicherer politischer Faktor war. Großfürst Vytautas wollte selbstständiger Herrscher werden und die Oberhoheit von Jagieło verlassen, was zur Auflösung der polnisch-litauischen Union hätte führen können. Sigismund unterstützte die Bestrebungen des litauischen Großfürsten und berichtete am 30. November I 428 dem Hochmeister darüber, dass er als römischer Kaiser Vytautas eine Krone geben und hierüber in der Stadt Luzk mit dem polnischen König und dem litauischen Fürsten verhandeln wolle. ${ }^{58}$ Die Unabhängigkeit von Litauen beförderte auch der Deutsche Orden, aber König Jagiełło hielt das für einen casus belli. In dieser Situation, in der ein bewaffneter Konflikt drohte, wollte der Hochmeister seine militärische Kraft nicht zwischen der preußisch-polnischen und der ungarisch-türkischen Grenze aufteilen, aber er wollte auch die Güte und politische Unterstützung von Sigismund nicht verlieren. Die Verzögerung der Antwort des Ordens kann auch damit erklärt werden, dass in einer Frage, wie der Verteidigung der Donaugrenzen in Ungarn, auch die Einwilligung des Generalkapitels nötig war. Ende 1428 besprach das Generalkapitel das Angebot von Sigismund und beauftragte den Hochmeister, es anzunehmen, wenn er die Umstände angemessen fände. ${ }^{59}$ Die endgültige Entscheidung konnte der Hochmeister treffen. Paul von Rusdorf fand die Situation noch nicht reif, Ritter zur Niederdonau zu schicken, weil sie dort sofort mit den Türkenkriegen hätten anfangen sollen und keine Möglichkeit zum Ausbau ihrer Position im Banat von Severin gehabt hätten. Der Hochmeister teilte seine Besorgnisse über Ritter von Redewitz Sigismund mit, weil der König in seinem Brief vom I 8. Februar I 429 aus Kaschau betonte, dass er einen Waffenstillstand von drei Jahren schließen wolle und die nach Ungarn kommenden Ritter nicht sofort Krieg führen sollten. Die Jahre des Waffenstillstandes würden genug Vorbereitungszeit auf künftige Kriege sichern. ${ }^{60}$ Am 7. April 1429 kam eine türkische Delegation nach Ofen und schloss mit Ungarn einen Waffenstillstand von drei Jahren $a b .{ }^{61}$ Um die Sache der Verteidigung der Grenze entlang der Niederdonau zu befördern, versprach Sigismund in seinem Brief an den Hochmeister, dass er dem Orden die Provinz Neumark nicht nur als Pfand, sondern als Eigentum geben werde, wenn die Ritter nach Ungarn kämen. ${ }^{62}$ Sigismund schickte am 17. April I 429 wieder einen Brief, in dem er den Hochmeister drängte, Brückenbaumeister

58 GStA PK, XX. HA, OBA, Nr. 5008; Giedrè Mickũnaite, Making a Great Ruler: Grand Duke Vytautas of Lithuania (Budapest-New York: CEU, 2006), 7.

s9 Glück, "A Német Lovagrend," 35.

60 Regesta Imperii, XI, 2, hrsg. v. Böhmen, Nr. 7 I 7 I (Fenesan Nr. I 4).

61 Codex epistolaris Vitoldi Magni Ducis Lithuaniae 1376-1430, pars I, hrsg. v. Antoni Prochaska (Cracoviae: Academiae Literarium, I 882), Nr. 1348.

62 Regesta Imperii, XI, 2, hrsg. v. Böhmen, Nr. 7 I 7 I (Fenesan Nr. I 4). 
Hans von Ratibor nach Ungarn zu schicken. Er teilte dem Hochmeister auch mit, wie die Vorbereitungen für die Niederlassung des Deutschen Ordens im Banat von Severin ständen. ${ }^{63}$ Man kann vermuten, dass auf das Angebot von Sigismund eine positive Antwort kam und der Hochmeister Ende März oder Anfang April eine Entscheidung traf. Paul von Rusdorf schrieb am 23. April 1429 einen Brief an den Landmeister von Livland, dass der ungarische König den Orden mit Gebieten und Burgen entlang der Donau in der Nähe von Serbien belehne und er im Gegenzug dafür Ritter nach Ungarn schicke, die unter der Leitung von Nicolaus von Redewitz die Grenzverteidigung gegen die Türken entlang der Donau organisieren. ${ }^{64}$ Der Brief suggeriert, dass auf Vermittlung von Nicolaus von Redewitz Sigismund und der Hochmeister nach langen Verhandlungen vereinbarten, dass nicht Truppen des Ordens nach Ungarn kommen, sondern der Hochmeister einige Ritter nach Ungarn schickt, die sich in der Grenzverteidigung auskennen. Der Hochmeister hielt den nach Ungarn reisenden Rittern eine Unterweisung in der Burg Stuhm und gab ihnen einen Brief für von Redewitz voll mit Instruktionen mit. Hierin stand, dass der Deutsche Orden Sigismund und seine Frau gerne als Ehrenmitglied in den Orden aufnehmen könnten. Die abfahrenden Truppen des Ordens nahmen Devotionalien, Kirchengeräte und religiöse Bücher mit. Die Urkunde hierüber erwähnt nur sieben Ritter, ${ }^{65}$ aber späteren Briefen zufolge fuhren viel mehr Ritter aus Preußen ab. Die auf November 1429 datierten Briefe berichten auch darüber, dass zusammen mit den Rittern Brückenbaumeister Hans von Ratibor nach Ungarn gekommen sei. ${ }^{66}$ In einer Urkunde vom 7. März I 432 kann man eine Liste der Ritter, die in das Banat von Severin kamen, finden. Hier wurden nicht nur sieben, sondern dreizehn Namen erwähnt. ${ }^{67}$ Der Name des Brückenbaumeisters wird jedoch nicht erwähnt. Man kann also annehmen, dass neben den namentlich genannten noch viel mehr Menschen aus dem Staat des Deutschen Ordens an die Donau kamen. Die Urkunde vom I. Juli I 433 erwähnt den Ritter Eberhard Sax als Kapitän von Szentlászlóvár, aber sein Name taucht in keinen früheren Dokumenten auf. ${ }^{68}$ Die Anzahl der Ritter des Ordens, die unter der Leitung

\footnotetext{
${ }_{63}$ Ebd., Nr. 72 i 5 (Fenesan Nr. I6).

${ }_{64}$ GStA PK, XX. HA, OBA, Nr. 5074 (Fenesan Nr. 17); Liv-, Est- und Kurländisches Urkundenbuch, Bd. VII, I423 Mai - I429 Mai, hrsg. v. Friedrich G. von Bunge (Riga: Deubner, I 88 I - I 889), Nr. 80 I.

65 GStA PK, XX. HA, OBA, Nr. 5096 (Fenesan Nr. I 8).

66 GStA PK, XX. HA, OBA, Nrn. $5211,5236$.

67 GStA PK, XX. HA, OBA, Nr. 5999 (Fenesan Nr. 39).

68 Pesty, Krassó vármegye története, III: 344-346 Nr. 246 (Fenesan Nr. 44).
} 
von Nicolaus von Redewitz in das Banat von Severin kamen, um die Grenzverteidigung zu organisieren, kann man auf zwei bis drei Duzend schätzen. ${ }^{69}$

\section{Der Deutsche Orden an der Niederdonau}

Gemäß dem Brief von Sigismund an den Hochmeister vom 30. Juli i 429 kamen die Ritter aus Preußen Ende Juli an den Hof, der damals in Preßburg weilte. Von hier aus fuhren sie unter der Leitung von Nicolaus von Redewitz und in Begleitung von mehreren königlichen Amtsinhabern nach Südungarn, um die dortigen Burgen und Gebiete, die ihnen zuteilwurden, in Besitz zu nehmen. Der König bat den Hochmeister, noch mehr Soldaten und Handwerker zu schicken. ${ }^{70}$ Die Ritter des Ordens nahmen die Burgen im Banat von Severin im August 1429 in Besitz. Über die schnelle Übergabe müssen Ritter von Redewitz und die königlichen Amtsinhaber Sigismund auf dem Laufenden gehalten haben. Der König muss mit der Vorgehensweise zufrieden gewesen sein, weil er gemäß seinem Versprechen am 7. September I 429 auf die verpfändete Provinz Neumark verzichtete und sie in das Eigentum des Deutschen Ordens gab. ${ }^{71}$ Er unterrichtete den Hochmeister zwei Tage später darüber, dass seine Amtsinhaber, wie vereinbart, Nicolaus von Redewitz und seinen Ordensmitgliedern die vorher bestimmten Burgen übergeben hätten, und versicherte dem Leiter des Ordens, dass er die Ritter bei der Verteidigung der Südgrenzen unterstützen werde. ${ }^{72}$ Neben seiner Rolle bei der Grenzverteidigung beachtete Sigismund auch die Gesandtenfunktion von Nicolaus von Redewitz und teilte ihm - seinen politischen Interessen gemäß - viele Informationen mit. Er schickte am 3. September 1429 dem an der Südgrenze weilenden Ritter den Brief, den der Hochmeister dem litauischen Großfürsten geschrieben hatte, damit der Gesandte des Ordens über die Verhandlungen zwischen dem Hochmeister und dem polnischen König aus erster Hand informiert sei. Weiterhin teilte er dem Ritter böhmische Geschehnisse mit, damit er Marienburg darüber informieren konnte. ${ }^{73}$ Laut den Urkunden kam Ritter von Redewitz

\footnotetext{
69 Viorel Achim, "Locul Ordinului Teuton în îstoria Banatului de Severin," Banatica 24 (2014): 38.

70 GStA PK, XX. HA, OBA, Nr. 5148 (Fenesan Nr. 20); Regesta Imperii, XI, 2, hrsg. v. Böhmen, Nr. 7349 .

${ }_{71}$ Regesta Imperii, XI, 2, hrsg. v. Böhmen, Nrn. 7398, 7403, 7408; Die Staatsverträge des Deutschen Ordens in Preußen im I5. Jahrhundert, Bd. I, $1398-1437$, hrsg. v. Erich Weise (Marburg: N. G. Elwert, I970, 2. Auflage), Nr. I 68.

72 GStA PK, XX. HA, OBA, Nr. 517 I (Fenesan Nr. 22).

73 Regesta Imperii, XI, 2, hrsg. v. Böhmen, Nr. 7396.
} 
nach der Inbesitznahme der Burgen im Banat von Severin an den Hof von Sigismund zurück, weil er als Ratgeber des Königs nicht lange vom Hof abwesend sein konnte. Ende September 1429 berichtete er dem Hochmeister über die Geschehnisse am Hof, wie zum Beispiel über die Ankunft der Gesandten des litauischen Großfürsten Vytautas..$^{74}$ Laut einer späteren Urkunde vom I 9 . August 1432 wurde er im Banat von Severin vom Ritter Oswald Weyler vertreten. (Sein Name wurde in den vorherigen Urkunden nicht erwähnt.) ${ }^{75}$ Nicolaus von Redewitz blieb bis Ende September oder Anfang Oktober am Hof von Sigismund, wo er Zeuge der Aufnahme des Großfürsten Vytautas in den Orden des Drachen war. Im Herbst I 429, im Oktober oder im November (das genaue Datum ist unbekannt), fertigte er einen Bericht über den Zustand der dem Deutschen Orden übergebenen Burgen und Garnisonen in Severin an, weiterhin berichtete er darüber, welche Vorschläge er dem König gemacht hatte, um die Verteidigungsfähigkeit der Burgen zu vergrößern und die Anzahl der Besatzung zu erhöhen. ${ }^{76}$ Er hat auch Weihnachten in Südungarn verbracht, denn er schickte am I 3. Januar I 430 einen Brief aus der Burg Mehadia (ung. Miháld). ${ }^{77}$ Sigismund erließ am 23. und 24. Dezember 1429 zwei Urkunden in Preßburg, die dem Orden Privilegien in Deutschland gewährten..$^{78} \mathrm{Ob}$ diese Urkunden mit der schnellen Lagebeurteilung und den Lösungsvorstellungen des Ritters von Redewitz an der Niederdonau zu tun hatten, wissen wir nicht.

Die Vorschläge von von Redewitz waren Sigismund wegen der langen Verhandlungen, die der Teilnahme des Deutschen Ordens an der Verteidigung der Donaugrenzen vorangingen, nicht unbekannt. Der Gesandte des Ordens wollte die Besatzung der Garnisonen der zwölf Palisaden, weiterhin der ungefähr i 5$-30 \mathrm{~km}$ hinter den Palisaden stehenden anderen drei Burgen und der $30-40 \mathrm{~km}$ dahinter stehenden weiteren drei Burgen (insgesamt i 8) um I 370 Fußsoldaten (wovon 328 Armbrustschützen waren) und um 550 Ritter erhöhen. Die Donauflotte wollte er mit I 40 neuen Schiffen und mit einer Besatzung von I 400 Soldaten verstärken. Die Kavallerie wollte er in den von Feinden bedrohten Gebieten mit I 50 leichten Reitern schlagfähiger machen. Bei der Mehrheit der Burgen hielt er die Verstärkung oder den Umbau der Wände und der Festungen für notwendig. Laut seiner Kostenberechnung beliefen sich die vorgeschlagene Erhöhung der Anzahl der Soldaten und die Kosten des Schiff- und Burgenbaus auf 3 I 4822

\footnotetext{
74 GStA PK, XX. HA, OBA, Nr. 5192.

75 GStA PK, XX. HA, OBA, Nr. 6196.

76 GStA PK, XX. HA, OBA, Nr. 27837 (Fenesan Nr. 23).

77 Urkundenbuch zur Geschichte des Deutschen in Siebenbürgen, Bd. IV, hrsg. v. Gustav Gündisch (Hermannstadt: Michaelis, I 937), Nr. 2083 (Fenesan Nr. 26).

78 Regesta Imperii, XI, 2, hrsg. v. Böhmen, Nrn. 7523, $7533 \mathrm{a}$.
} 
goldene Forint. ${ }^{79} \mathrm{Um}$ alle nötigen Maßnahmen treffen zu können, ernannte Sigismund von Redewitz zum Ban von Severin (banus Zewriniensis) und überließ den Rittern, wie vorher versprochen, unterschiedliche königliche Einkommen zur Finanzierung der militärischen Ausgaben. Über diese Entscheidungen berichtete Nicolaus von Redewitz dem Hochmeister ausführlich. Der König überließ den Rittern das Einkommen der Münzanstalten von Hermannstadt und Kronstadt (ungefähr I 50000 Forint) und ernannte von Redewitz zum Kammergrafen von Hermannstadt (comes monetarum cibiniensis). (Nur ein Teil des Einkommens der Münzanstalten von Kronstadt bekamen die Ritter, der andere Teil gehörte der Stadt.) Sigismund versprach den Rittern 60000 Forint aus dem Einkommen der siebenbürgischen Silberbergwerke und Salz im Wert von 100000 Forint aus den vier südlichen Salzkammern, für dessen Verkauf die Ritter selbst sorgen müssten. Weiterhin befahl er dem Woiwoden von Siebenbürgen, den Rittern, etwa alle drei Jahre 50 Ochsen und 50 Schafe zu geben. Er versprach den Rittern das Einkommen des Weinzehntels des Erzbistums Kalocsa und I 3,5 Quintal Weizen und Hafer aus den privilegierten Gebieten der Kumanen und Jazygen. ${ }^{80}$ Dieses Einkommen hätte eine ausreichende finanzielle Basis für die südliche Grenzverteidigung bieten können, doch in Wirklichkeit bekamen die Ritter nur ein Teil dessen (wie das Weinzehntel des Erzbistums Kalocsa und das Getreide der Gebiete der Jazygen und Kumanen). Sie erhielten wahrscheinlich nur Silber im Wert von 60000 Forint aus den Silberbergwerken, das Einkommen der siebenbürgischen Münzanstalten, das höchstens 100000 Forint wert gewesen sein konnte und Salz im Wert von 100000 Forint. Die Summe, die von Redewitz vom König erbat (3 1 4822 goldene Forint), war für ungarische Verhältnisse sehr hoch und betrug ungefähr ein Drittel des Einkommens des königlichen Fiskus. ${ }^{81}$ Sigismund brauchte aber auch Geld für die Verteidigung der anderen Grenzen, ganz zu schweigen von den Kriegsausgaben, z.B. für die Kriege gegen die Hussiten. ${ }^{82}$ Das Geld, das die Ordensritter beanspruchten, bekamen sie nie. Im Brief vom 7. März I 432, den von Redewitz nach Marienburg schickte, beschwerte er sich, dass der König sein Versprechen, das er vor der Niederlassung der Ritter im Banat von Se-

79 GStA PK, XX. HA, OBA, Nr. 27837 (Fenesan Nr. 24); Glück, “A Német Lovagrend”" 37-39; Pósán, "A Német Lovagrend," 280-284.

8० GStA PK, XX. HA, OBA, Nr. 27837 (Fenesan Nr. 25); Mályusz, Zsigmond király, i I 7; Jörg K. Hoensch, "König/Kaiser Sigismund, der Deutsche Orden und Polen-Litauen," Zeitschrift für Ostmitteleuropa-Forschung 46, H. I (1997): 32; Pósán, "A Német Lovagrend," 284.

${ }_{8}$ Pál Engel, “A magyar királyság jövedelmei Zsigmond korában," in A tudomány szolgálatában. Emlékkönyv Benda Kálmán 8o. születésnapjára, hrsg. v. Ferenc Glatz (Budapest: MTA TTI, I 993), 28.

82 Engel, "Ungarn und die Türkengefahr," 69. 
verin gemacht hatte, nicht erfüllt habe und von Redewitz die Burgen und Grenzen gegen die Türken so nicht verteidigen könne. Er bat den Hochmeister, den König um die notwendigen Verteidigungsmittel zu bitten. ${ }^{{ }_{3}}$

Nach den Urkunden kam Nicolaus von Redewitz als Leiter des ritterlichen Kontingents nach Südungarn und versuchte als Ban von Severin möglichst viel Zeit auf seinem Posten zu verbringen, musste aber als Gesandter des Hochmeisters und Ratgeber von Sigismund oft am königlichen Hof sein. Im Januar I 430 schrieb er noch aus Südungarn einen Brief, ${ }^{84}$ der nächste Brief von ihm datiert vom I 4. Mai I 430. Hier berichtete er dem Hochmeister darüber, dass sich Vytautas beim König über den Deutschen Orden wegen des Bistums Ösel beklagt habe und Graf Ulrich Cillei, der Neffe des Königs, auf die Iberische Halbinsel gepilgert sei. ${ }^{85}$ Diese Informationen muss er sich am königlichen Hof und nicht in Südungarn verschafft haben. Er muss also vom Spätherbst I 429 bis Ende März oder Anfang April 1430 im Banat von Severin gewesen sein, und dann an den Hof von Sigismund zurückgekehrt sein. Irgendwann in Sommer kam er wieder an die Niederdonau, weil er schon am i 8 . Juli 1430 in der Burg von Haram Recht sprach. ${ }^{86}$ Am 21. August 1430 schrieb er schon auch aus der Burg von Haram einen Brief an den König, in dem er berichtete, dass die Adligen und Kenesen von Severin lieber vor dem Gericht des Königs als dem des Severiner Bans erschienen. ${ }^{87}$ Bis zum Frühling I 43 I blieb er in Südungarn und beschäftigte sich mit der Organisation des wichtigsten Festungsbaus an der Grenze. ${ }^{88}$ Als Leitung einer Burg bestimmte er je einen Ritter und legte auch die Aufgaben der anderen Ritter fest. Hiervon berichtete er dem Hochmeister ausführlich in seinem Brief vom 7. März I $432 .{ }^{89}$ Neben den militärischen Aufgaben musste er als Ban von Severin auch das Alltagsleben des Banats leiten, wie er in seinen Briefen vom I 3. Januar I 430 und vom 2 1. August 1430 schrieb..$^{\circ \circ}$ Was er in Südungarn machte, teilte er dem Hochmeister in einem Brief vom 21. August I 430 mit. Er verschwieg nicht, dass die Aktivität des Ordens nicht von jedem in Ungarn begrüßt werde, da über

\footnotetext{
83 GStA PK, XX. HA, OBA, Nr. 5999 (Fenesan Nr. 39).

${ }_{4}$ Urkundenbuch, IV, hrsg. v. Gündisch, Nr. 2083 (Fenesan Nr. 26).

8s GStA PK, XX. HA, OBA, Nr. 5365 . Über die Pilgerfahrt von Ulrich Cillei siehe Ignacij Voje, "Romanje Ulrika II. Celjskega v Kompostelo k Sv. Jakobu," Zgodovinski Casopis 38 (1984): 225-230.

86 Urkundenbuch, IV, hrsg. v. Gündisch, Nr. 2096 (Fenesan Nr. 27).

87 Pesty, A szörényi bánság, 24-25 Nr. 37.

88 Mark Whelan, Sigismund of Luxemburg and the Imperial Response to the Ottoman Turkish Threat c. 1410-1437 (London: University of London, Dissertation, 2014 ), I 6 I.

89 GStA PK, XX. HA, OBA, Nr. 5999 (Fenesan Nr. 39).

90 Pesty, A szörényi bánság, 24-25 Nr. 37; Urkundenbuch, IV, hrsg. v. Gündisch, Nrn. 2083, 2096 (Fenesan Nrn. 26, 27).
} 
ihn Verleumdungen und unbegründete Gerüchte verbreitet worden seien. Die den Rittern versprochenen Summen würden Neid hervorrufen und auch von Redewitz selbst werde beneidet, weil er als Fremder und Gesandter eines anderen Staates Ratgeber des Königs, Kammergraf von Hermannstadt und Ban von Severin geworden sei. Um seinen und den Ruf des Ordens zu schützen, bat er den Hochmeister, auf seine Ämter in Ungarn verzichten und nach Preußen zurückkehren zu dürfen. ${ }^{91}$ Nach den Urkunden willigte der Hochmeister darin nicht ein, sondern bat ihn sogar noch mehr Zeit am Hof zu verbringen, weil die Krönung von Vytautas und damit die Auflösung der polnisch-litauischen Union vor der Tür stünden..$^{92} \mathrm{Im}$ Juli I 430 thematisierte Sigismund in mehreren Briefen die bevorstehende Krönung von Vytautas. ${ }^{93}$ Die Soldaten des Ordens nahmen auch an den Kriegen gegen die Hussiten teil, ${ }^{94}$ weshalb der Hochmeister die ständige diplomatische Vertretung bei Sigismund sehr wichtig fand. Einen ähnlichen Auftrag muss von Redewitz schon vorher aus Marienburg bekommen haben, da er seinen Brief vom 6. August I 43 I, in dem er um seine Rückkehr ersuchte, weder aus Südungarn, noch überhaupt aus Ungarn, sondern aus der Stadt Nürnberg schrieb, wo er Ende des Winters zusammen mit der Gefolgschaft von Sigismund ankam. Der Kaiser schrieb am 25. Februar von hier einen Brief an den Hochmeister, in dem er über die aktuellen polnischen und litauischen Angelegenheiten berichtete und darüber, dass er mit den deutschen Fürsten einen Kreuzzug gegen die Hussiten vorbereite.95 Am 27. April I 43 I schrieb auch Ritter von Redewitz von hier einen Brief an den Hochmeister über die deutschen und italienischen politischen Fragen und die Beschwerden des fränkischen Adels über den Deutschmeister. ${ }^{96}$ Auch in seinem Brief vom 6. August, in dem er die Schwierigkeiten der ungarischen Grenzverteidigung thematisierte, standen Fragen der europäischen Politik (Sigismunds Absicht im Herbst nach Rom in Italien zu fahren, Angelegenheiten mit den Türken usw.) im Mittelpunkt. Er berichtete auch darüber, dass mehrere junge deutsche Adlige in den Deutschen Orden aufgenommen worden seien. ${ }^{77}$ Wenn der königliche Hof und auch Nicolaus von Redewitz Ende Februar I43 I in Süddeutschland waren, muss der Ritter spätestens in der ersten Hälfte vom Januar I 43 I Südungarn verlassen haben. Laut der Urkunde vom 19. August I 432 beauftragte er seinen

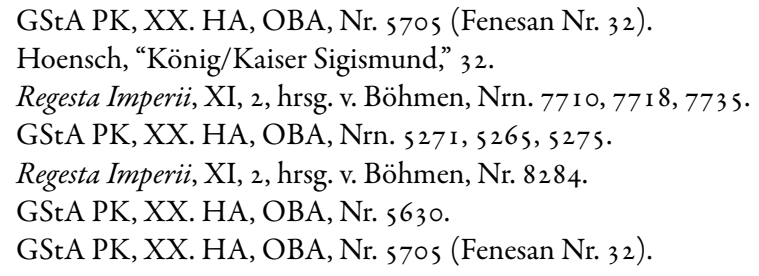


Stellvertreter Oskar Weyler mit den Aufgaben in Südungarn. ${ }^{98}$ In Süddeutschland übertrug der Kaiser von Redewitz finanzielle Aufgaben: In seinem Brief vom 7. Mai I 43 I aus Nürnberg befahl der Kaiser ihm mit jüdischen Gemeinschaften und Bankiers des Reiches über die Auslösung der von der Krone aufgenommenen Kredite und Renten in einer Summe und die so konkret zu bezahlenden Summen zu verhandeln. ${ }^{99}$ Diese Urkunde beweist, dass Nicolaus von Redewitz über finanzielle Kenntnisse und Verhandlungsvermögen verfügte, die es ermöglichten, ihn zum Kammergrafen von Hermannstadt zu wählen, der die siebenbürgische Münzprägung beaufsichtigten und über die Auslösung der königlichen Kredite verhandeln konnte. Von Redewitz schien erfolgreich zu sein, denn er konnte sich am I 3. Juni I 43 I mit den jüdischen Bankiers aus Augsburg und am 28. Juni mit denen aus Schweinfurt schnell einigen. ${ }^{100}$ Nach dem Brief von von Redewitz vom 6. August schrieb selbst der Kaiser am I 8 . August an den Hochmeister, dass er wegen der Lösung seiner finanziellen Probleme den Gesandten des Ordens nach Italien nicht mitnehme, so dass der Ritter für eine Weile nicht in seiner Umgebung sein werde. ${ }^{101}$ Nicolaus von Redewitz blieb in Nürnberg und schickte einen Bericht nach Preußen, dass der österreichische Herzog Albert erfolgreich gegen die Hussiten gekämpft habe. ${ }^{102}$ Sigismund wurde am 25 . November I 43 I zum König von Italien gekrönt. ${ }^{103}$ Ende 143 I oder Anfang 1432 kehrte von Redewitz nach Ungarn zurück und erfuhr, dass die Festungsarbeiten an den Burgen im Banat von Severin noch nicht vollendet waren und die versprochenen finanziellen Mittel nur zum Teil eingekommen waren. ${ }^{104}$ Hiervon unterrichtete er den Hochmeister am 7. März I 432. Irgendwann Ende des Frühlings, Anfang des Sommers reiste er, vermutlich auf Weisung von Sigismund, wieder nach Deutschland. Laut einem Brief vom I9. August I 432 aus der Burg Sebes schickte sein Stellvertreter Oswald von Weyer einen Kurier nach ihm und bat die weltlichen und kirchlichen Würdenträger, die Güter entlang des Weges Ofen-Wien hatten, dem Kurier Martin Roheph, der wahrscheinlich einer der Ritter aus Preußen war, die nach Südungarn kamen, bei seiner Reise zu helfen. ${ }^{105}$ Er wollte aller Wahrscheinlichkeit nach seinen Vorgesetzten schnellst möglich über die türkischen Bewegungen und

98 GStA PK, XX. HA, OBA, Nr. 6 1 96 (Fenesan Nr. 42).

99 Regesta Imperii, XI, 2, hrsg. v. Böhmen, Nr. 8573.

100 Ebd., Nrn. 861 5, 865 I.

${ }^{101}$ Ebd., Nr. 8793.

${ }^{102}$ GStA PK, XX. HA, OBA, Nr. 5787.

${ }^{103}$ Péter E. Kovács, “Zsigmond király milánói koronázása," in Tiszteletkör. Történeti tanulmányok Draskóczy István egyetemi tanár 6o. születésnapjára, hrsg. v. Gábor Mikó, Bence Péterfi, und András Vadas (Budapest: ELTE Eötvös, 2012), 67-83.

${ }^{104}$ GStA PK, XX. HA, OBA, Nr. 5999 (Fenesan Nr. 39).

ros GStA PK, XX. HA, OBA, Nr. 6196 (Fenesan Nr. 42). 
Truppenkonzentrationen an der Südgrenze informieren. Der drei Jahre zuvor mit den Türken I 429 geschlossene Waffenstillstand lief Ende des Winters I 432 ab. Die Türken hatten den Waffenstillstand schon im Jahr zuvor außer Acht gelassen, als ihre Truppen im Burzenland umherzogen. ${ }^{106}$ Diese Grenzverletzung deutete schon auf einen seriöseren Überfall hin. Franko Tallóci, der Gespan der Komitate Csanád, Keve und Karasch, Kapitän von Nándorfehérvár rief am 5. August I 432 dazu auf, wegen der türkischen Bewegungen die Besatzung von Szentlászlóvár zu verstärken. ${ }^{107}$ János, Bischof von Agram und königlicher Kanzler, berichtete dem in Siena verbliebenen König am 25. August I 432, dass die Türken in Ungarn eingedrungen seien. ${ }^{108}$ Sie drangen beim Eisernen Tor ein, wo der Deutsche Orden auf sie wartete. ${ }^{109}$ Das Heer von Vlad Dracul, des Fürsten der Walachei und Vasallen des Sultans, und die türkischen Truppen eroberten drei unter Aufsicht des Deutschen Ordens stehende Burgen an der Donau. Diese wurden abgebrannt und ihre Garnisonen massakriert. ${ }^{10}$ Der im Dienst von Sigismund stehende Eberhard Windecke schrieb in seinen Memoiren das Folgende: ,in demselben Jahr, als Seine Majestät in der Lombardei war [...] drangen die Türken in Ungarn ein [...] und sie wollten die hier weilenden preußischen Herren aus dem Gebiet verjagen, das der römische König ihnen in Ungarn überließ [...]". ${ }^{111}$ Ende des Sommers 1432 fielen die Burgen Severin, Orschowa und Pét den Türken zum Opfer, die anderen Burgen an der Donau blieben jedoch in der Hand des Ordens. Die Türken versuchten auch die stärkste Burg in Südungarn Szentlászlóvár zu erobern, scheiterten aber daran. Windecke schrieb hierüber in seinen Memoiren: „Die Ungarn besiegten die Türken, sie töteten und ertränkten 60.000 oder mehr von ihnen, unter denen gab es sogar Venezianer [...].“.12 Der Leiter der ungarischen Truppen bei Szentlászlóvár war gemäß einer Urkunde seit Ende Juni 1433 Eberhard Sax, ein Ritter des Deutschen Ordens. ${ }^{113}$

\footnotetext{
${ }^{106}$ Adinel C. Dincă, "Der Türkeneinfall im Burzenland aus dem Jahre I 43 I. Die unbekannten Glossen einer siebenbürgischen Handschrift," Transylvanian Review 25 (2016): 133-1 42.

107 Pesty, Krassó vármegye története, III: 343-344 Nr. 245 (Fenesan Nr. 4I).

${ }^{108}$ GStA PK, XX. HA, OBA, Nr. 6203.

109 Glück, "A Német Lovagrend," 42.

110 GStA PK, XX. HA, OBA, Nr. 6276.

${ }_{11}$ Berhard Windecke emlékirata Zsigmond királyról és koráról, hrsg. v. Renáta Skorka (Budapest: MTA TTI, 2008), 25 I.

${ }_{112}$ Ebd.

${ }_{113}$ Pesty, Krassó vármegye története, III: 344 Nr. 246 (Fenesan Nr. 44).
} 


\section{Der Deutsche Orden nach dem türkischen Anfall von 1432}

Der Überfall der Türken im Jahre I 432 hat große Verluste verursacht, bedeutete aber nicht den Zusammenbruch des Systems der Grenzburgen oder die Vernichtung des Deutschen Ordens in Südungarn. In der Fachliteratur wird dieses Geschehen so beurteilt, dass der Überfall der Türken dem Deutschen Orden im Banat von Severin einen so harten Schlag versetzte, dass dieser Ungarn I 433 sehr schnell verließ. ${ }^{114}$ Die Tatsachen und die Quellen widersprechen dieser Vermutung jedoch. Die ungarische Seite des Eisernen Tors schützte die Burg Szentlászlóvár und die Flotte auf der Donau, von der ein großer Teil bei dieser Burg stationiert war. Die zweite Verteidigungslinie hinter der Donau brach auch nicht zusammen, doch mit dem Fall von Severin, Orschowa und Pét wurde die Grenzverteidigung viel schwieriger. Sigismund von Luxemburg schickte am 2 I. Februar I 433 aus Siena einen Brief an den Hochmeister, in dem er ihn über den türkischen Überfall und die Verluste des Ordens in Südungarn informierte. ${ }^{15}$ Über diese Geschehnisse muss auch von Redewitz berichtet haben, aber sein Brief (oder seine Briefe) ist (sind) nicht erhalten geblieben. Er schlug vielleicht die Aufgabe des Grenzschutzes an der Niederdonau vor, aber Marienburg willigte darin nicht ein. Dies hing wahrscheinlich damit zusammen, dass Sigismund und der Deutsche Orden in den Fragen von Litauen und den Hussiten politisch und militärisch verbündet waren. ${ }^{116}$

Aber nicht nur der Brief von Ende Juni I 433, der Eberhard Sax als Kapitän von Szentlászlóvár erwähnt, beweist, dass der Deutsche Orden die Donaugrenzen nach dem Überfall der Türken im Jahre 1432 weiterhin verteidigte. Am 29. November I 433 gab Sigismund Redewitz den Auftrag als Ban von Severin und als Amtsträger des Königs dem Ritter Nikolaus von Bizere die Güter, die der König von seinem Vater und seinen Verwandten wegen Treubruchs konfiszierte, zurückzugeben. ${ }^{17}$ Nicolaus Redewitz muss den Brief, der am 2. Januar 1434 am Hof des Hochmeisters ankam, in der ersten Hälfte vom Dezember 1433 geschrieben haben. Hier schrieb er über den großen Schlag des Ordens im Banat von Severin und drohte mit der Aufgabe des Grenzschutzes in Südungarn, wenn der König das nö-

${ }_{114}$ Achim, "Locul Ordinului Teuton," 38 ; Hochstrasser, "Der Ordenspraeceptor Nicolaus von Redewitz," I 27; Hoensch, "König/Kaiser Sigismund," 32.

i1s GStA PK, XX. HA, OBA, Nr. 6366.

${ }_{116}$ Regesta Imperii, XI, 2, hrsg. v. Böhmen, Nrn. 8 535, 8793; Hoensch, "König/Kaiser Sigismund," 36; Manfred Hellmann, Grundzüge der Geschichte Litauens (Darmstadt: WBG, 1976) 39-40; Klaus Militzer, Die Geschichte des Deutschen Ordens (Stuttgart: Kohlhammer, 2005), I 50 ; Mályusz, Zsigmond király, , $о 0$.

117 Pesty, A szörényi bánság, III: 26-27 Nr. 40 (Fenesan Nr. 45). 
tige Geld nicht zur Verfügung stelle, weil die finanziellen Mittel für die Deckung der Kosten nicht ausreichend seien. ${ }^{118}$ Dieser Brief beweist, dass der Deutsche Orden anderthalb Jahre nach dem Angriff der Türken immer noch im Banat von Severin war und versuchte, die Grenzen zu schützen. In einer Urkunde vom I 2. März I 435 wird Nicolaus von Redewitz noch als Ban von Severin (Nicolaus de Radawicz crucifero ordinis Prutenorum Zeuriniensi banis) erwähnt. ${ }^{19}$ Eine andere Urkunde vom 29. April I 434 aus Basel erwähnt ihn als Mitglied des kaiserlichen Hofgerichts. ${ }^{120}$ Dass Sigismund dem Gesandten des Ordens neben ungarischen Titeln und Ämtern auch Reichswürden verlieh, war eine wichtige Geste dem Orden gegenüber und ein Zeichen, dass er dem Orden bei seiner Politik eine wichtige Rolle geben wollte. Er brauchte den Orden, um die militärischen Kräfte der Polen und der Hussiten zu binden. Er plante einen Kriegszug für den Sommer I 435, um seinen litauischen Verbündeten zu helfen, und wollte dabei auch dem Orden eine wichtige Funktion geben. Hiermit hing wahrscheinlich auch zusammen, dass er im August 1435 dem Orden eine Verleihungsurkunde ausstellte. ${ }^{121}$ Aber nach den Fragen und Beschwerden von Nicolaus von Redewitz muss Sigismund eingesehen haben, dass die Grenzverteidigung in der Form, wie sie sich der Orden vorstellte, nicht finanzierbar war, da er während seines Aufenthaltes in Siena einen umfangreichen Plan für die ungarische Kriegsmacht und das Schutzsystem vorbereitete, den er zur Konsultation an die Komitate schickte. Einige Teile dieses Plans wurden im Landtag von Preßburg im Jahre I 435 angenommen. ${ }^{122}$ Man kann vermuten, dass der König versuchte, den Deutschen Orden an der Grenze zu halten, bis die ungarischen Stände die wichtigsten Elemente seines militärischen Plans akzeptierten. Nachdem der König in die Wünsche von von Redewitz eingewilligt und dem Orden erlaubt hatte, nach Preußen zurückzukehren, ließ er den Orden nicht auf einmal, sondern nur stufenweise gehen, abhängig davon. wie schnell er einen Ersatz organisieren konnte. Der ehemalige Kapitän von Orschowa Erwin Haug von Heiligenberg kehrte schon ziemlich früh, Ende I434, nach Preußen zurück, da sein Name in einer Urkunde von 1435 als Hauskomtur von Marienburg erwähnt wird. ${ }^{123}$ In der Urkunde vom I 2 . März 1435 erschien nicht mehr der

\footnotetext{
${ }_{118}$ Joachim, “König Sigismund," Nr. 7.

119 Urkundenbuch, IV, hrsg. v. Gündisch, Nrn. 2175 (3 I. Mai I 433), 2214 (2. September I 434); Regesta Imperii, XI, 2, hrsg. v. Böhmen, Nr. 10765.

${ }_{120}$ Regesta Imperii, XI, 2, hrsg. v. Böhmen, Nr. 103 I 5.

${ }_{121}$ Regesta Historico-Diplomatica ordinis S. Mariae Theutonicorum IIg8-I525, Pars II, Regesta Privilegiorum Ordinis S. Mariae Theutonicorum, Mit einem Anhang: Papst-und Konzilsurkunden, hrsg. v. Erich Joachim und Walther Hubatsch (Göttingen: Vandenhoeck \& Ruprecht, 1949), Nr. 2388.

${ }_{122}$ Ágoston, Európa, 69.

${ }_{123}$ GStA PK, XX. HA, OBA, Nr. 7 I 14.
} 
Name von Nicolaus von Redewitz als Ban von Severin, diese Funktion wurde im Jahre 1436 von Frankó Tallóci erfüllt. ${ }^{124}$ Als die Ritter Ungarn verließen, schaffte der König die unterschiedlichen Ämter von von Redewitz allmählich ab. In seinem Brief vom 6. November 1435 bat er den Hochmeister wegen des finanziellen Rechnungsabschlusses von Redewitz Ritter aus Preußen nach Ungarn zu schikken, damit sie sich von der Fairness des Verfahrens überzeugen könnten. ${ }^{125}$ Dabei muss auch der Gesundheitszustand von Nicolaus von Redewitz eine Rolle gespielt haben, da Sigismund in seinem Brief vom 3 I. Januar I 437 aus Prag an den Hochmeister berichtete, dass der Gesandte des Ordens gestorben sei. ${ }^{126}$ Zum Zeitpunkt seines Todes gab es noch Ritter an der Donaugrenze. Am 23. Juni 1437 schickte der König zwei Briefe nach Marienburg, in denen der König Matthis Kycka, dem vorherigen Kellermeister in der Burg von Severin, und Kaspar Götz, Kapitän der Burg Görény, erlaubte, nach Preußen zurückzukehren. ${ }^{27}$ Die deutschen Ritter, die I 429 nach Ungarn kamen, standen also nach dem Überfall der Türken im Jahre I 432 noch Jahre lang in Südungarn im Dienst von Sigismund.

\section{Primay SOURCES:}

Berlin. Geheimes Staatsarchiv Preußischer Kulturbesitz. XX. HA, Ordensbriefarchiv, Nrn. 40 I O, 4378, 4397, 4398, 4407, 4738, 3741, 4749, 4759, 4787, 4794, 4795, 4990, 5008, 5074, 5096, 5 I 48, 5 I 7 I, 5 I 92, 52 II, 5236, 5265, 5271, 5275, 5365, 5630, 5705, $5787,5999,6196,6203,6276,6366,7083,7$ I I 4, 733 I, 7332, 27837.

Berhard Windecke emlékirata Zsigmond királyról és koráról. Herausgegeben von Renáta Skorka. Budapest: MTA TTI, 2008.

Die Berichte der Generalprokuratoren des Deutschen Ordens an die Kurie. Bd. II. Peter von Wormditt (1403-I4I9). Herausgegeben von Kurt Forstreuter und Hans Koeppen. Göttingen: Vandenhoeck \& Ruprecht, I96I.

Codex diplomaticus Prussicus. Bd. VI. Herausgegeben von Johannes Voigt. Königsberg: Gebrüder Bornträger, I 861.

Codex epistolaris Vitoldi Magni Ducis Lithuaniae 1376-1430. Pars I. Herausgegeben von Antoni Prochaska. Cracoviae: Academiae Literarium, I 882.

Deutsche Reichstagakten unter Kaiser Sigmund. Bd. IX. Herausgegeben von Dietrich Kerler. München: Oldenburg, I 887.

Documenti diplomatici tratti dagli archivi milanesi. Herausgegeben von Luigi Osio. Milano: Tip. ei G. Bernardoni di Giovanni, 1872.

\footnotetext{
${ }^{124}$ Engel, "Ungarn und die Türkengefahr," 70.

125 GStA PK, XX. HA, OBA, Nr. 7083 (Fenesan Nr. 48).

${ }^{126}$ Regesta Imperii, XI, 2, hrsg. v. Böhmen, Nr. I 1653.

${ }_{127}$ GStA PK, XX. HA, OBA, Nr. 7331, 7332.
} 
Itineraria regum et reginarum (1382-1438). Herausgegeben von Pál Engel und Norbert C. Tóth. Budapest: Magyar Országos Levéltár, 2017.

Liv-, Est- und Kurländisches Urkundenbuch. Bd. VII. 1423 Mai - I429 Mai. Herausgegeben von Friedrich G. von Bunge. Riga: Deubner, I 88 I - I 889 .

Regesta Historico-Diplomatica ordinis S. Mariae Theutonicorum IIg8-1525. Pars II. Regesta Privilegiorum Ordinis S. Mariae Theutonicorum. Mit einem Anhang: Papst-und Konzilsurkunden. Herausgegeben von Erich Joachim und Walther Hubatsch. Göttingen: Vandenhoeck \& Ruprecht, I 949.

Regesta Imperii XI. Die Urkunden Kaiser Sigmunds (I4I0-I437). Bd. I-2. Herausgegeben von Johann Friedrich Böhmen. Innsbruck: Wagner, I 896-1 900.

Die Staatsverträge des Deutschen Ordens in Preußen im I5. Jahrhundert. Bd. I. 1398-I437. Herausgegeben von Erich Weise. Marburg: N. G. Elwert, 1970. 2. Auflage.

Urkundenbuch zur Geschichte des Deutschen in Siebenbürgen. Bd. IV. Herausgegeben von Gustav Gündisch. Hermannstadt: Michaelis, I 937.

Zsigmondkori Oklevéltár. Bd. VI. Herausgegeben von Elemér Mályusz und Iván Borsa. Budapest: Akadémiai, I 999.

Zsigmondkori Oklevéltár. Bd. IX. Herausgegeben von Norbert C. Tóth. Budapest: Magyar Országos Levéltár, 2004.

Zsigmondkori Oklevéltár. Bd. XIII. Herausgegeben von Norbert C. Tóth und Gábor Mikó. Budapest: Magyar Országos Levéltár, 2017.

\section{SECONDARY SOURCES}

Achim, Viroel. "Der Stellenwert des Deutschen Ordens in der Geschichte des Banats von Severin." In Generalprobe Burzenland: Neue Forschungen zur Geschichte des Deutschen Ordens in Siebenbürgen und im Banat. Harald Zimmermann zum 85. Geburtstag, herausgegeben Konrad Gündisch, I77-ı 88. Köln-Weimar-Wien: Böhlau, 20 I 3.

Achim, Viroel. "Locul Ordinului Teuton în îstoria Banatului de Severin." Banatica 24 $(2014): 37-46$.

Ágoston, Gábor. Európa és az oszmán hóditás. Budapest: HM HIM, 2014.

Atiya, Aziz Suryal. The Crusade of Nikopolis. London: Meuthen, I 943.

Bárány, Attila. "Magyarország és a kései keresztes hadjáratok." In Magyarország és a keresztes háborúk. Lovagrendek és emlékeik, herausgegeben von József Laszlovszky, Judit Majorossy, und József Zsengellér, I 46- I 49. Máriabesnyő-Gödöllő: Attraktor, 2006.

Bezold, Friedrich von. König Sigmund und die Reichskriege gegen die Hussiten. München: Ackermann, 1872.

Cîmpeanu, Liviu. "Den al II-lea, Sigismund de Luxemburg si cruciada târzie. Un document inedit din archiva Ordinului teutoni." Studii si materiale de istorie medie 30 (2012): 55-75.

Ciocîltan, Virgil. "Sigismund von Luxemburg und die Frage der Verpflanzung des Deutschen Ordens an die Untere Donau in den Jahren I 4 I 2- I 420." In Generalprobe Burzenland: Neue Forschungen zur Geschichte des Deutschen Ordens in Siebenbürgen 
und im Banat. Harald Zimmermann zum 85. Geburtstag, herausgegeben von Konrad Gündisch, I60-1 76. Köln-Weimar-Wien: Böhlau, 20 I 3 .

Dincă, Adinel C. "Der Türkeneinfall im Burzenland aus dem Jahre I 43 I. Die unbekannten Glossen einer siebenbürgischen Handschrift." Transylvanian Review 25 (2016): I33- I 42.

Ekdahl, Sven. "Der Krieg zwischen dem Deutschen Orden und Polen-Litauen im Jahre I 422." Zeitschrift für Ostforschung I 3, H. 4 ( I 964): 6 I 4-65 I.

Engel, Pál. "A magyar királyság jövedelmei Zsigmond korában.” In A tudomány szolgálatában. Emlékkönyv Benda Kálmán 8o. születésnapjára, herausgegeben von Ferenc Glatz, 27-3 I. Budapest: MTA TTI, I 993.

Engel, Pál. "Ungarn und die Türkengefahr zur Zeit Sigismunds (1387-1437)." In Das Zeitalter König Sigismunds in Ungarn und im Deutschen Reich, herausgegeben von Tilmann Schmidt und Péter Gunst, 55-7 r. Debrecen: DUP, 2000.

Favreau-Lilie, Marie-Luise. "Der Deutsche Orden in Norditalien (1 3. Jh.). Über die Grenzen der 'Netzwerkforschung'." Ordines Militares Colloquia Torunensia Historica. Yearbook for the Study of the Military Orders 20 (20 I 5): 39-64.

Fenesan, Costin. Cavalerii teutoni în Banatul Severinului si la Dunarea de jos in prima jumatate a seocolului al XV-lea: documente si extras. Timişoara: Cosmopolitan-Art, 2015.

Fenesan, Costin. "Cavalerii teutoni in Banatul Severinului si la Dunărea de jos în prima jumătate a secolului al XV-lea. Documente si extrase." Banatica 26 (2016): 6-55.

Fodor, Pál. The Unbearable Weight of Empire. The Ottomans in Central Europe - A Failed Attempt at Universal Monarchy (I390-I566). Budapest: MTA BTK TTI, 2015.

Forstreuter, Kurt. "Der Deutsche Orden und Südosteuropa." Kyrios I (1 936): 245-272.

Glück, Jenő. “A Német Lovagrend a XV. századi Bánságban.” Zounuk. A Szolnok Megyei Levéltár Évkönyve I 8 (1993): 33-44.

Glück, Jenő. "Date noi cu pivire la prezența cavelerilor teutoni la frontiera Banatului ( $1429-1$ 437).” Revista Istorică N.F. 3 ( 1 992): 783-792.

Hațegan, Ioan. "Cavalerii teutoni în Banatul Severinului (I 429-I 435)." Tibiscus 5 (1 979): I 91-I 96.

Hellmann, Manfred. Grundzüge der Geschichte Litauens. Darmstadt: WBG, I 976.

Hoensch, Jörg K. Kaiser Sigismund. Herrscher an der Schwelle zur Neuzeit 1368-1437. München: C. H. Beck, I 996.

Hoensch, Jörg K. "König/Kaiser Sigismund, der Deutsche Orden und Polen-Litauen." Zeitschrift für Ostmitteleuropa-Forschung 46, H. I ( 1997 ): I-44.

Hochstrasser, Gerhard. "Der Ordenspraeceptor Nicolaus von Redwitz und die Münzprägung in Siebenbürgen und im Seweriner Banat im I 5. Jahrhundert." In Beiträge zur Geschichte des Deutschen Ordens. Bd. 2, herausgegeben von Udo Arnold, I 24-I 34. Marburg: Elwert, 1993.

Hóvári, János. “A nikápolyi csata. Fordulópont a balkáni oszmán hódítások történetében.” Hadtörténelmi Közlemények I I I ( I 998): 578-582. 
Joachim, Erich. "König Sigmund und der deutsche Ritterorden in Ungarn I 429-1 432. Mitteilungen des Instituts für Österreichische Geschichtsforschung 33, H. I ( 9 I 2): 87- I I 9.

Jóźwiak, Sławomir. "Der Bau, Wiederaufbau und Ausbau der Nogatbrücke gegenüber der Marienburg vom I 4. bis zu den Anfängen des i 5. Jahrhunderts." In Studies of the Military Orders, Prussia and Urban History: Essays in Honour of Roman Czaja on the Occasion of his Sixtieth Birthday / Beiträge zur Ritterordens-, Preussen- und Städteforschung. Festschrift für Roman Czaja zum 6o. Geburtstag, herausgegeben von Jürgen Sarnowsky, Krzysztof Kwiatkowski, Hubert Houben, László Pósán, und Attila Bárány, 26 I-272. Debrecen: University of Debrecen, 2020.

Kemény, Joseph. "Die durch König Sigmund im Jahre 1426 beabsichtigte Wiederansiedlung des deutschen Ordens in Siebenbürgen.” In Magazin für Geschichte, Literatur und alle Denk- und Merkwürdigkeiten Siebenbürgens. Bd. II/I, herausgegeben von Anton Kurz, 98-99. Kronstadt: Johann Gott, i 846.

Kovács, Péter E. “Zsigmond király milánói koronázása." In Tiszteletkör. Történeti tanulmányok Draskóczy István egyetemi tanár 6o. születésnapjára, herausgegeben von Gábor Mikó, Bence Péterfi, und András Vadas, 67-83. Budapest: Eötvös, 2012.

Kuhn, Walter. "Ritterorden als Grenzhüter des Abendlandes gegen das östliche Heidentum." Ostdeutsche Wissenschaft 6 (1959): 7-70.

Lacko, Miroslav, und Erika Mayerová. Das älteste Stadtbuch von Schmöllnitz I4Io-I735. Eine Quelle zu den mitteleuropäischen wirtschaftlichen Verflechtungen. Limbach: Slovenská spoločnost pre sociálne a hospodárske dejiny, 20 I 6.

Lückerath, Carl August. Paul von Rusdorf. Hochmeister des Deutschen Ordens I422-I44I. Bad Godesberg: Wissenschaftliches Archiv, I 969.

Mályusz, Elemér. Zsigmond király uralma Magyarországon 1387-1437. Budapest: Gondolat, 1984.

Matuz, József. Az Oszmán Birodalom története. Budapest: Akadémiai, I 990.

Mickũnaitè, Giedrè. Making a Great Ruler: Grand Duke Vytautas of Tlithuania. Budapest-New York: CEU, 2006.

Militzer, Klaus. Die Geschichte des Deutschen Ordens. Stuttgart: Kohlhammer, 2005.

Montogna, Victor. "Banatul românesca în prima jumătate a secolului XV. Epocha lui Sigismund de Luxemburg (1395-1438).” In Banatul de altădată. Studii istorice, herausgegeben von Cornel Grofşorean, 449-480. Timişoara: Institutului Social Banat-Crişana, I 944.

Nemoianu, Alexandru. "Unele aspecte privind prezența teutonilor în Banat ( I 429-I 432).” Muzeul Național 2 (1975): 38 I-386.

Nistor, Ioan I. Ţara Severinului şi Banatul Timişan. Bucuresti: Monitorul Oficial si Imprimeriile Statului, I 945.

Papacostea, Şerban. "Kilia et la politique orientale de Sigismund de Luxembourg." Revue Roumaine d'Historie Is ( I 976): 42 I-436.

Pálffy, Géza. "A török elleni védelmi rendszer szervezetének története a kezdetektől a I 8. század elejéig." Történelmi Szemle 38 ( 1996): I63-2 I 7. 
Pesty, Frigyes. A szörényi bánság és Szörény vármegye története. Bd. I-III. Budapest: Akadémiai, I 878.

Pesty, Frigyes. Krassó vármegye története. Bd. I-III. Budapest: Athenaeum, I 882.

Pósán, László. “A Német Lovagrend szerepe Magyarország déli határainak védelmében (1429-1435).” In Örzök, vigyázzatok a határra! Határvédelem, határörizet, határvadászok a középkortól napjainkig, herausgegeben László Pósán, László Veszprémy, József Boda, und János Isaszegi, 263-292. Budapest: Zrínyi, 2017.

Pósán, László. "Die politischen Bestrebungen und Ziele Polen-Litauens auf dem Konstanzer Konzil." In Der Deutsche Orden auf dem Konstanzer Konzil. Pläne - Strategien - Erwertungen, herausgegeben von Helmut Flachenecker, 89-105. Quellen und Studien zur Geschichte des Deutschen Ordens 84. Würzburg: Forschungsstelle Deutscher Orden an der Universität Würzburg, 2020.

Pósán, László. “Zsigmond és a Német Lovagrend." Hadtörténelmi Közlemények i I I (I 998): 85- i I 2.

Skorka, Renáta, und Boglárka Weisz. "A porosz kapcsolat. Johann Falbrecht és David Rosenfeld a magyar pénzügyigazgatásban.” In Hatalom, adó, jog. Gazdaságtörténeti tanulmányok a magyar középkorról, herausgegeben von István Kádas und Boglárka Weisz, i 8 I-207. Budapest: MTA BTK TTI, 20 I 7.

Stromer, Wolfgang von. "Zsigmond császár Velence elleni kontinentális zárlata és a nemzetközi kereskedelmi utak áthelyeződése." Századok I 2 I ( I 987): 638-659.

Țeicu, Dumitru. “Cetăti medievale din Banat," Reşita: Muzeul Banatului Montau (2009): I I-I 6 .

Thumser, Matthias. "Eine neue Aufgabe im Heidenkampf? Pläne mit dem Deutschen Ordens als Vorposten gegen die Türken.” In Europa und die Türken in der Renaissance, herausgegeben von Bodo Gurthmüller und Wilhelm Kühlmann, I39-176. Tübingen: Niemeyer, 2000.

Trâpcea, Theodor N. "Despre unele cetăți medievale din Banat." Studii de istorie a Banatului I (1 969): 23-82.

Voigt, Johannes. Geschichte Preussens von den ältesten Zeiten bis zum Untergang der Herrschaft des Deutschen Ordens. Bd. 7. Königsberg: Gebrüder Bornträger, I 836.

Voje, Ignacij. "Romanje Ulrika II Celjskega v Kompostelo k Sv. Jakobu." Zgodovinski Casopis 38 (1984): 225-230.

Whelan, Mark. "Catastrophe or Consolidation? Sigismund's Response to Defeat after the Crusade of Nicopolis ( 1396 )." In Between Worlds: The Age of the Jagiellonians, herausgegeben von Florin Ardelean, Christopher Nicholson, und Johannes Preiser-Kapeller, 2 I 5-227. Frankfurt/Main: Peter Lang, 2013.

Whelan, Mark. Sigismund of Luxemburg and the Imperial Response to the Ottoman Turkish Threat c. I4IO-1437. London: University of London, Dissertation, 2014.

Zimmermann, Harald. Der Deutsche Orden in Siebenbürgen. Eine diplomatische Untersuchung. Köln-Weimar-Wien: Böhlau, 20 I I.

Zimmermann, Harald. "Europäische Politik und Türkenabwehr zur Zeit Sigismunds des Luxemburgers." In Harald Zimmermann, Siebenbürgen und seine Hospites Teutonici. 
Vorträge und Forschungen zur südostdeutschen Geschichte. Festgabe zum 7o. Geburtstag, herausgegeben von Konrad Gündisch, I 23-1 30. Köln-Weimar-Wien: Böhlau, I 996. Zimmermann, Harald. “Kaiser Sigismund von Luxemburg und Siebenbürgen.” In Harald Zimmermann, Siebenbürgen und seine Hospites Teutonici. Vorträge und Forschungen zur südostdeutschen Geschichte. Festgabe zum 7o. Geburtstag, herausgegeben von Konrad Gündisch, I I 4-I 22. Köln-Weimar-Wien: Böhlau, I 996. 